\title{
Isolation and Characterization of Dominant Fungi from Rhizospheric Soil of Saussurea obvallata (DC.) Edgew. (Brahma Kamal) of the Indian Himalayan Region
}

\author{
Debasis Mitra $^{1}$ (D) Anju Rani ${ }^{2 *}$ (D), Lok Man S. Palni ${ }^{1}$, Komal Sharma ${ }^{1}$ (D) Navendra \\ Uniyal $^{1}{ }^{(D)}$, Akansha Chauhan ${ }^{1}(\mathbb{D})$ Prabhakar Semwal $^{1}(\mathbb{D}$ and Poonam Arya² \\ ${ }^{1}$ Department of Biotechnology, ${ }^{2}$ Department of Life Sciences, Graphic Era (Deemed to be University), \\ Dehradun - 248 002, Uttarakhand, India.
}

\begin{abstract}
The Himalayan region is conferred by diverse wealth in term of flora and fauna. Among Himalayan plant biodiversity, Saussurea obvallata (common name Brahma Kamal) has an immense spiritual and medicinal significance. Owing to high demand, this herb is on the verge of extinction. Numerous studies have been carried out for preservation and in vitro regeneration of Saussurea obvallata. In view of above, this is the first study which aims to isolate and identify rhizospheric fungi associated with this plant. Soil samples were collected from three locations in Kedarnath valley and total $\mathbf{3 4}$ fungal isolates were isolated. Out of 34, three fungal isolates i.e. MaHaD1, MaHaD2 and MaHaD3 were selected for morphological and molecular characterization. The $16 \mathrm{~S}$ rDNA sequencing identified MaHaD1, MaHaD2 and MaHaD3 as Phanerochaete chrysosporium, Trichoderma longibrachiatum and Aspergillus fumigatus respectively. The presence of these three dominant fungi in rhizospheric region seems to be results of climatic conditions and plant physiology. Results indicate that the presence of fungal microflora may play a vital role in survival and proliferation of Saussurea obvallata plant by providing tolerance and resistance to abiotic stress and fungal/nematode pathogens respectively.
\end{abstract}

Keywords: Saussurea obvallata, Aspergillus fumigatus, Phanerochaete chrysosporium, Trichoderma longibrachiatum, Rhizospheric soil, rDNA-ITS Sequencing.

*Correspondence: teotia_anju29@rediffmail.com; +91-9557945779

(Received: 10 May 2019; accepted: 22 June 2019)

Citation: Debasis Mitra, Anju Rani, Lok Man S. Palni, Komal Sharma, Navendra Uniyal, Akansha Chauhan, Prabhakar Semwal and Poonam Arya, Isolation and Characterization of Dominant Fungi from Rhizospheric soil of Saussurea obvallata (DC.) Edgew. (Brahma Kamal) of the Indian Himalayan Region, J Pure App/ Microbiol., 2019; 13(3): 1509-1515. https://doi.org/10.22207/JPAM.13.3.22

(C) The Author(s) 2019. Open Access. This article is distributed under the terms of the Creative Commons Attribution 4.0 International License which permits unrestricted use, sharing, distribution, and reproduction in any medium, provided you give appropriate credit to the original author(s) and the source, provide a link to the Creative Commons license, and indicate if changes were made. 


\section{INTRODUCTION}

Saussurea obvallata (DC.) Edgew. (Brahma Kamal) is one of the valuable traditional herb of the Himalayan region belonging to the family Asteraceae ${ }^{1}$. Generally, it is found in different states of the Indian Himalayan region (Kashmir, Himachal Pradesh, Uttarakhand, Sikkim and Arunanchal Pradesh) and other countries (Nepal, Bhutan, Myanmar, China and Pakistan) ${ }^{2}$ with an altitudinal range from $3,000-4,800 \mathrm{~m}$ above mean sea level $\left.\right|^{3,4,5}$. The whole plant of Saussurea obvallata is used by the local people of the Himalaya, for traditional, cultural, and religious purposes $^{6,7}$. The Conservation Assessment and Management Plan (CAMP) had categorized Saussurea obvallata as an endangered species. Several investigations have been carried out to study reproductive biology, genetic diversity, cultivation and propagation of S. obvallata in view of conservation and management of the endangered medicinal herb ${ }^{3,6}$ (Fig. 1). To the best of our knowledge, no study has been done to study rhizospheric microbes of Saussurea obvallata till now. As rhizospheric microflora plays an important role in germination, growth and survival of plant in respective niche. In order to know the role of rhizospheric microflora in growth of Saussurea

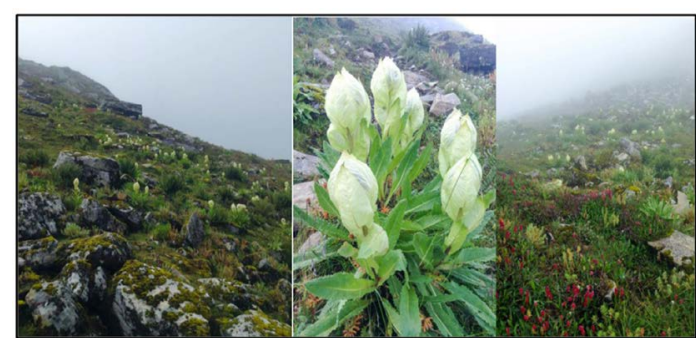

Fig. 1. Soil sample collection sites (Photo: P. Semwal)

Table 1. Growth conditions and collection site details of selected isolates

\begin{tabular}{lccc}
\hline $\begin{array}{l}\text { Isolate } \\
\text { Name }\end{array}$ & \multicolumn{2}{c}{ Growth Conditions } \\
Temperature & Medium & Soil \\
MaHaD1 & $25 \pm 3.0^{\circ} \mathrm{C}$ & $\begin{array}{c}\text { Fungal Broth } \\
\text { and PDA } \\
\text { Sungal Broth } \\
\text { MaHaD2 }\end{array}$ & MG \\
MaHaD3 & $25 \pm 3.0^{\circ} \mathrm{C}$ & $\begin{array}{c}\text { Fund PDA } \\
\text { angal Broth } \\
\text { Fung } \\
\text { and PDA }\end{array}$ & HP \\
\hline
\end{tabular}

obvallata, this study was conducted to isolate the fungal community of Saussurea obvallata rhizospheric region. In the present study, we revealed that the potential fungal community present in the rhizospheric soil of Saussurea obvallata.

\section{MATERIALS AND METHODS Isolation of Fungus}

The rhizospheric soil samples of Saussurea obvallata were collected from Madhu Ganga (MG), HathiParwat (HP) and MahaPanth (MP) in Kedarnath Valley (Fig. 1), Uttarakhand, India ${ }^{8}$. The samples were packed and sealed in plastic bags and immediately brought to the laboratory and stored in refrigerator till further use. The three soil samples were serially diluted and $100 \mu$ l of dilution sample $\left(10^{0-5}\right)$ was plated onto potato dextrose agar (PDA) (CDH, JO-0013, India) supplemented with antibiotic ( $50 \mathrm{mg} \mathrm{L}^{-1}$ of chloramphenicol) for the isolation of fungi and incubated for seven days at $20^{\circ} \mathrm{C}$.

\section{Morphology of Isolates}

The fungi were identified based on the macroscopic (colony morphology, texture) and microscopic (fruiting bodies i.e. conidia and hyphae) culture characters. For microscopic identification fungal isolates were stained with lactophenol cotton blue stain and were observed at $40 x$ and $100 x$. The classifications of the fungi were carried out following standard procedures. All the isolated fungi were named and stored in fungal broth containing $15 \%(\mathrm{v} / \mathrm{v})$ glycerol at $-20^{\circ} \mathrm{C}$ for further use.

\section{DNA extraction, gene amplification and sequencing}

Genomic DNA was isolated from the isolates viz. MaHaD1, MaHaD2 and MaHaD3 using the ultrapure DNA isolation kit.The identification of isolates carried out by internal spacer transcribed (ITS) region amplification and sequencing. The ITS region of rDNA was amplified by PCR using fungal universal primer pairs ITS4 and ITS5 ${ }^{9}$. The sequencing PCR was set up with ABI BigDye ${ }^{\circledR}$ Terminatorv3.1 Sequence kit. The raw sequences were obtained from $A B I 3100$ automated DNA sequencer and aligned with publicly available sequences and analyzed for identification. 


\section{Sequence analysis and Multiple sequence alignment}

The sequence data were aligned using BLASTN 2.8.1 (https://blast.ncbi.nlm.nih.gov/ Blast.cgi) and sequences were deposited in NCBI (https://submit.ncbi.nlm.nih.gov/subs/genbank/) for accession number. The phylogenetic analysis was done via. MEGA6-ClustalW sequence program followed by evolutionary tree constructionusing software MEGA6based on the Tamura-Neimode ${ }^{10}$. Multiple sequence alignment (MSA) of fungal isolates i.e. MaHaD1, MaHaD2 and MaHaD3 were carried out using T-Coffee (Version_11.00. d625267)(http://tcoffee.crg.cat/), a consistencybased MSA program ${ }^{11}$.

Deposition of fungus isolates in culture collection center

MaHaD1, MaHaD2 and MaHaD3 fungal isolates were deposited in the National Fungal Culture Collection of India (NFCCI) (http://nfcci. aripune.org/) for the accession no. and future research works.

\section{RESULTS AND DISCUSSION \\ Fungal Isolates}

Total 34, 29 and 31 fungal isolates were isolated from rhizospheric soil samples of Saussurea obvallata collected from MG, HP and MP sites respectively. For further study one fungal isolate (MaHaD1, MaHaD2 and MaHaD3) from each collection site i.e. MG, MP and HP were selected on the basis of the best growth (Table 1). Morphological identification

Morphological identification of MaHaD1, MaHaD2 and MaHaD3 isolates were carried out using of lactophenol cotton blue staining method (Fig. 2). The colony appearance and microscopic morphological details revealed by staining are summarized in Table 2.

\section{Molecular identification}

The ITS sequence of Phanerochaete chrysosporium MaHaD1 showed $99 \%$ maximum similarity with accession no. HM171940.1, MH854905.1, MG646957.1, KT188591.1 and KP135093.1 sequences while Trichoderma longibrachiatum MaHaD2 showed $97 \%$ similarity with accession no. MG836641.1, MG836590.1, MK015045.1, MF632112.1 and KY495196.1. Third isolate i.e. Aspergillus fumigatus MaHaD3 showed 98\% similarity with accession no. MH185963.1,
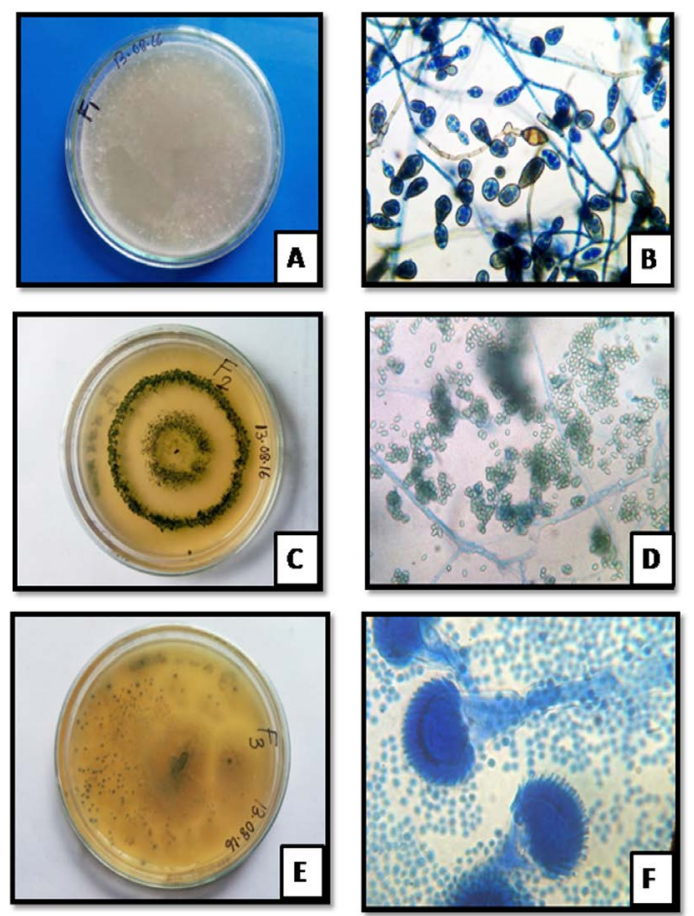

Fig. 2. Colony morphology of MaHaD1 (A) MaHaD2 (C) and MaHaD3 (E) isolates on PDA plate (after 48hrs at $28^{\circ} \mathrm{C}$ ) respectively; Microscopic structure of MaHaD1 (B) MaHaD2 (D) and MaHaD3 (F) isolates at 100x respectively.

Table 2. Colony morphology and microscopic details of selected isoates

\begin{tabular}{ll}
\hline Isolates Name & Morphological details \\
\hline MaHaD1 & $\begin{array}{l}\text { White cottony colonies, septate hyphae, club-shaped basidia, cylindrical to } \\
\text { ellipsoidal shaped spores }\end{array}$ \\
MaHaD2 & $\begin{array}{l}\text { Colony greenish-yellowish coloured, conidia shape is globose/ ellipsoidal/ } \\
\text { obovoidal, or short-cylindrical } \\
\text { MaHaD3 }\end{array}$ \\
& Green colored colony, echinulate conidia borne directly on broad clavate \\
vesicles
\end{tabular}


MG972741.1, MH305231.1, MH305230.1 and MH305226.1 from nBLAST. Isolates molecular identification details from NCBI database are shown in Table 3.

\section{Phylogenetic Analysis and MSA}

Strain name and accession no. of the related fungus was retrieved from NCBIBLAST and MSA was performed using ClustalW. Phylogenetic tree for the same data was obtained by neighbor joining method with Bootstrap values 1000 alignment with HM171940.1, MH854905.1, MG646957.1, KT188591.1, KP135093.1, MG836641.1, MG836590.1, MK015045.1, MF632112.1, KY495196.1, MH185963.1, MG972741.1, MH305231.1,
MH305230.1, MH305226.1, MH911420.1, MH911400.1 and evolutionary tree shown in Fig. 3. MSA of Phanerochaete chrysosporium MaHaD1 (MK172050), Trichoderma longibrachiatum MaHaD2 (MK172051) and Aspergillus fumigatus (MK172052) in T-Coffee analysis (Fig. 4).

\section{Isolates deposite report}

All three fungal isolates (MaHaD1, MaHaD2 and MaHaD3) were submitted to National Fungal Culture Collection of India (NFCCI) and accesion no given to Phanerochaete chrysosporium MaHaD1 (MK172050), Trichoderma longibrachiatum MaHaD2 (MK172051) and Aspergillus fumigatus (MK172052) are NFCCI-4192, NFCCI-4193 and NFCCI-4194 respectively.

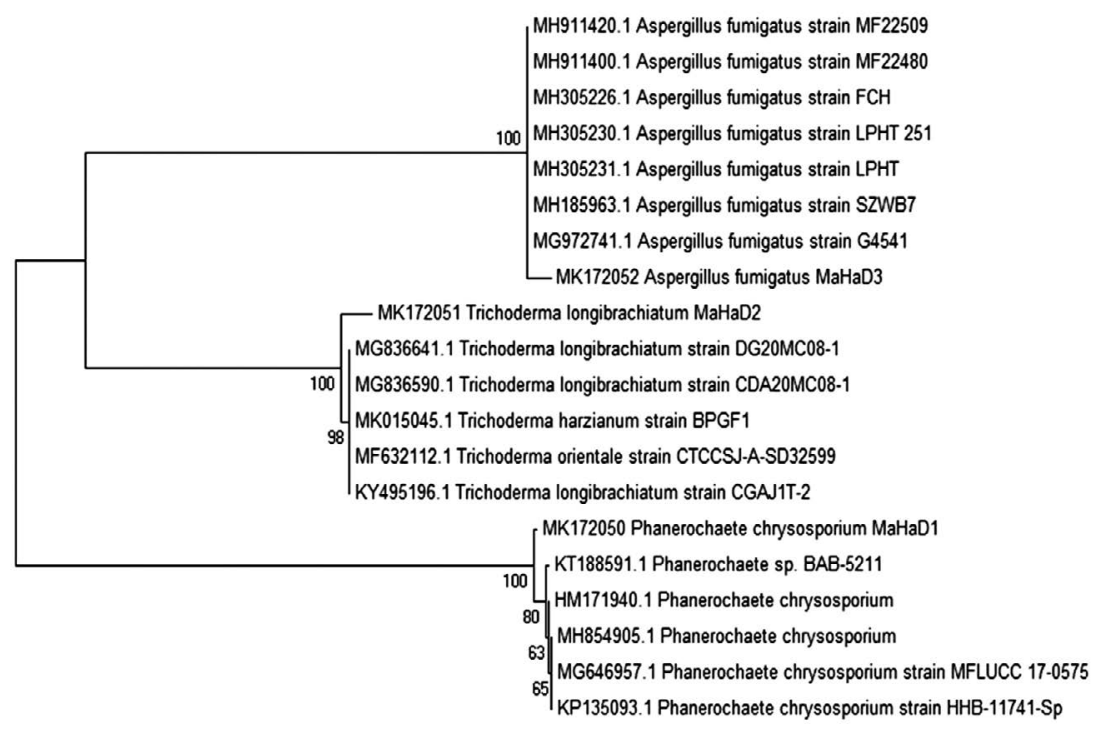

$\longmapsto 0.05$

Fig. 3. Neighbors joining molecular phylogenetic tree showing relationship between $P$. chrysosporium MaHaD1, $T$. longibrachiatum MaHaD2 and A. fumigatus with other isolates, based on their ITS sequence

Table 3. Molecular identification details of isolates

\begin{tabular}{lllllll}
\hline Isolates & $\begin{array}{l}\text { Isolates } \\
\text { identification }\end{array}$ & $\begin{array}{l}\text { Sequence } \\
\text { length }\end{array}$ & $\begin{array}{l}\text { Accession } \\
\text { no. }\end{array}$ & Ident & Ident & $\begin{array}{c}\text { Accession } \\
\text { no. }\end{array}$ \\
\hline MaHaD1 & P. chrysosporium & $584 \mathrm{bp}$ & MK172050 & $99 \%$ & $\begin{array}{l}\text { P. chrysosporium } \\
\text { isolate liu }\end{array}$ & HM171940.1 \\
MaHaD2 & T. longibrachiatum & $547 \mathrm{bp}$ & MK172051 & $97 \%$ & $\begin{array}{l}\text { T. longibrachiatum } \\
\text { strain DG20MC08-1 }\end{array}$ & MG836641.1 \\
MaHaD3 & A. fumigatus & $519 \mathrm{bp}$ & MK172052 & $98 \%$ & $\begin{array}{l}\text { A. fumigatus } \\
\text { isolate DFS 2 }\end{array}$ & MK116584.1 \\
\hline
\end{tabular}




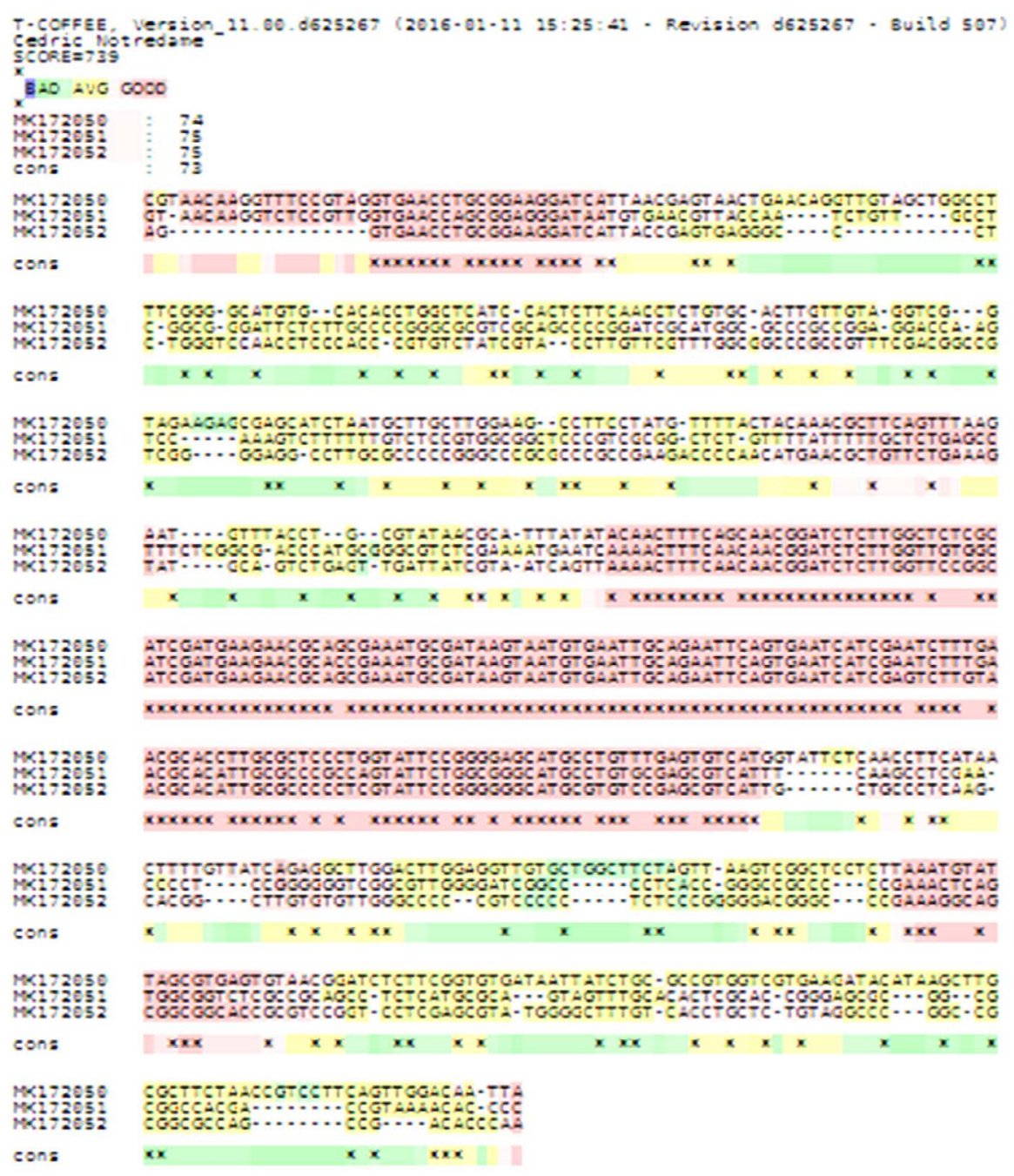

Fig. 4. MSA (T-Coffee) results of $P$. chrysosporium MaHaD1 (MK172050), T. longibrachiatum MaHaD2 (MK172051) and $A$. fumigatus (MK172052)

\section{DISCUSSION}

In our study, isolation, morphological and molecular characterization of fungal isolates from rhizospheric region of Saussurea obvallata suggested occourence of Phanerochaete chrysosporium, Trichoderma longibrachiatum and $A$. fumigatus as dominant genera. These fungal genera have effective role in organic decomposition, bioremediation and sustainable development ${ }^{12,13}$. Aspergillus fumigatus is saprophytic, airborne opportunistic pathogen. The ubiquitous prevalence of Aspergillus fumigatus in comparison to other sp. of Aspergillus is due to tolerance to various stresses (freezing, low $\mathrm{pH}$, dehydration) and growth on decaying vegetation and debris. Although Aspergillus fumigatus does not have any direct role in plant growth promotion, some studies reported vital role of Aspergillus fumigatus in $\mathrm{C}$ and $\mathrm{N}$ recycling ${ }^{14,15}$.

The Phanerochaete chrysosporium commonly known as white rot fungi ${ }^{16}$ is well known for digestion of fragrant poisons, lignin and lipids and remediation of various pollutants such as PAH, heavy metals and dyes ${ }^{17}$. Phanerochaete chrysosporium is considered an uncommon organism for its capacity to depolymerize and change lignin, cellulose and hemicellulose, in comparison with different basidiomycetes ${ }^{18}$. 
Trichoderma longibrachiatum uses cellulases to digest cellulose from decaying plant biomass, and chitinases to digest the chitinous walls of other fungi and nematode which indicate role of Trichoderma as a biocontrol agent ${ }^{19,20,21,22}$. Moscatiello et al. ${ }^{23}$ investigated that a mechanism of plant perception of HYTLO1, a hydrophobin abundantly secreted by T.longibrachiatum, which may assume an imperative role in the beginning times of the plant-parasite association. Some Trichoderma sp. are also known to provide tolerance/resistance to abiotic stresses, disease in addition to better plant growth ${ }^{24,22}$. The results suggest roles played by these fungal isolates in survival of S. obvallata plants. The probable mechanism of which may be by protecting plants from pests, inducing systemic resistance to plants for abiotic stress and improve soil nutrition acquisition. Further study is required to confirm the mechanism and role demonstrated by rhizospheric microorganisms in survival and growth of S. obvallata.

\section{ACKNOWLEDGEMENTS}

The authors are thankful to Agharkar Research Institute, Pune and National Fungal Culture Collection of India (NFCCI), Biodiversity and Palaeobiology Group, Agharkar Research, Pune and Graphic Era (Deemed to be University), Dehradun. We are also grateful to Dr. Ashish Thapliyal, Professor and Head, Department of Biotechnology, Graphic Era (Deemed to be University), Dehradun. First author thanks to Devvrat, Ph.D. Scholar, Graphic Era (Deemed to be University), Dehradun, Ansuman Senapati, SRF and Ph.D. Scholar, ICAR-NRRI for his help in Bioinformatics analysis.

\section{CONFLICT OF INTEREST} conflict of interest.

The authors declares that there is no

\section{AUTHORS' CONTRIBUTION}

LMSP and AR conceived the idea, designed the study, analyzed and interpreted data. DM, NU, KS and AC generated data. PS and PA provide the soil sample and screening. AR and DM drafted the paper and critically revised it for important intellectual content. All authors gave final approval of the version to be published.

\section{FUNDING}

We are grateful to the Founder and President, Prof. (Dr.) Kamal Ghanshala, Graphic Era (Deemed to be University), Dehradun and giving student research grants for this research work.

\section{DATA AVAILABILITY}

All data is freely available from the corresponding author on request.

\section{ETHICS STATEMENT}

Not applicable

\section{REFERENCES}

1. Bremer K. Asteraceae: Cladistics and Classification, Timber Press, Portland, Oregon,1994: 1-752.

2. Samant S.S, Dhar U, Palni LMS. Medicinal plants of Indian Himalaya-Diversity, Distribution. Diversity potential values, 1998: 163.

3. Butola J.S., Samant S.S., Saussurea species in Indian Himalayan Region: diversity, distribution and indigenous uses, Int. J. plant boil, 2010; 1(1): e9. https://doi.org/10.4081/pb.2010.e9.

4. Ghosh D, Brahma Kamal: The Himalayan Beauty. Resonance, 2017: 377-387. https://doi.org/10.1007/ s12045-017-0477-y.

5. Pant M., Semwal P., Brahma Kamal-the spiritually revered, scientifically ignored medicinal plant. Current Science, 2013; 104(6): 685-686.

6. Semwal P., Investigations on reproductive biology, genetic variation and medicinal properties of Saussurea obvallata (DC.) Edgew. in Uttarakhand. PhD Thesis submitted to Graphic Era University, Dehradun, Uttarakhand, India, 2017.

7. Tsarong T.J., Handbook of Traditional Tibetan Drugs: Their Nomenclature, Composition, use and Dosage, Tibetan Medical Publications, Kalimpong, 1986.

8. Semwal P., Palni L.M.S., Verma S., Sharma P., Thapliyal A. Nutrient Analysis of Rhizospheric and NonRhizospheric Soil of Saussurea obvallata (DC.) Edgew. (Brahma Kamal) from Kedarnath, Uttarakhand, India. Journal of Graphic Era University, 2018; 6(1): 1-6.

9. White T.J., Bruns T., Lee S.J.W.T., Taylor J.L. Amplification and direct sequencing of fungal ribosomal RNA genes for phylogenetics. PCR protocols: a guide to methods and applications, 1990; 18(1): 315-322. https://doi.org/10.1016/B978-0-12-372180-8.500421.

10. Tamura K., Nei M. Estimation of the number of nucleotide substitutions in the control region of mitochondrial DNA in humans and chimpanzees. Mol. Biol. Evol., 1993; 10: 512-526.

11. Di Tommaso P., Moretti S., Xenarios I., Orobitg M., Montanyola A., Chang J.M., Taly J.F, Notredame C. T-Coffee: a web server for the multiple sequence alignment of protein and RNA sequences using structural information and homology extension. Nucl. Acids Res., 2011, 39(suppl_2): W13-W17. https://doi.org/10.1093/nar/gkr245. 
12. Deshmukh R., Khardenavis A.A., Purohit H.J. Diverse metabolic capacities of fungi for bioremediation. Ind. J. Microbiol., 2016; 56(3): 247-264. https://doi.org/10.1007/s12088-016-0584-6.

13. Tortella G.R., Diez M.C., Duran N., Fungal diversity and use in decomposition of environmental pollutants. Critical Rev Microbio, 2005; 31(4): 197-212. https://doi.org/10.1080/10408410500304066.

14. Haines J. Aspergillus in compost: straw man or fatal flaw. Biocycle, 1995; 6: 32-35.

15. Pitt J.I. The current role of Aspergillus and Penicillium in human and animal health. J. Med. Vet. Mycol., 1994; S1: 17-32. https://doi.org/10.1080/02681219480000701.

16. Wu F., Ozaki H., Terashima Y., Imada T., Ohkouchi Y. Activities of ligninolytic enzymes of the white rot fungus, Phanerochaete chrysosporium and its recalcitrant substance degradability. Wat. Sci. Techno., 1996; 34(7-8): 69-78. https://doi.org/10.2166/ wst.1996.0603.

17. Sakai K., Matsuzaki F., Wise L., Sakai Y., Jindou S., Ichinose H., Takaya N., Kato M., Wariishi H., Shimizu M. Biochemical Characterization of CYP505D6, a Self-Sufficient Cytochrome P450 from the WhiteRot Fungus Phanerochaete chrysosporium. Appl. Environ. Microbiol., 2018; 84(22): e01091-18. https://doi.org/10.1128/AEM.01091-18.

18. Linares N.C., Fernandez F., Loske A.M., Gqmez-Lim M.A. Enhanced Delignification of Lignocellulosic Biomass by Recombinant Fungus Phanerochaete chrysosporium Overexpressing Laccases and Peroxidases. J. Mol. Microbiol. Biotechnol., 2018: 28(1): 1-13. https://doi.org/10.1159/000485976.
19. Chandra Mouli B. Global status of tea : Diseases and management strategies. In : Global Advances in Tea Science (Ed. Jain, N. K.). Aravali Books International (p) Ltd. New Delhi, 1999: 647-668.

20. Pandey A., Palni L.M.S., Bisht D. Dominant fungi in the rhizosphere of established tea bushes and their interaction with the dominant bacteria under in situ conditions. Microbiol. Res., 2001; 156: 377-382. https://doi.org/10.1078/0944-5013-00123.

21. Xie B.B., Qin Q.L., Shi M., Chen L.L., Shu Y.L., Luo Y., Wang X.W., Rong J.C., Gong Z.T., Li D., Sun C.Y. Comparative genomics provide insights into evolution of Trichoderma nutrition style. Genome Biol. Evol., 2014; 6(2): 379-390. https://doi.org/10.1093/gbe/evu018.

22. Zhang S., Gan Y., Xu B., Efficacy of Trichoderma longibrachiatum in the control of Heteroderaavenae. Biocontrol, 2014; 59: 319-331. https://doi. org/10.1007/s10526-014-9566-y.

23. Moscatiello R., Sello S., Ruocco M., Barbulova A., Cortese E., Nigris S., Baldan B., Chiurazzi M, Mariani P., Lorito M., Navazio L., The Hydrophobin HYTLO1 Secreted by the Biocontrol Fungus Trichoderma longibrachiatum Triggers a NAADP-Mediated Calcium Signalling Pathway in Lotus japonicus. Int. J. Mol. Sc., 2018; 19(9): 2596. https://doi.org/10.3390/ijms19092596.

24. Martinez C., Blanc F., Le Claire E., Besnard O., Nicole M., Baccou J.C. Salicylic acid and ethylene pathways are differentially activated in melon cotyledons by active or heat-denatured cellulase from Trichoderma longibrachiatum. Plant Physiol., 2001; 127: 334-344. https://doi.org/10.1104/pp.127.1.334 